\title{
Las aplicaciones robóticas inteligentes colaborativas en beneficio de la salud mundial y en la reducción de los efectos de la pandemia y pospandemia COVID 19 Collaborative Intelligent Robotic Applications for the Benefit of Global Health and in Reducing the Effects of the Pandemic and Post- Pandemic COVID 19
}

Adriana Margarita Porcelli* https://orcid.org/0000-0002-5192-5893

Adriana Norma Martínez** https://orcid.org/0000-0001-8962-2743

http://dx.doi.org/10.21503/lex.v19i27.2254

* Abogada-Procuradora (UBA) Magíster en Relaciones Internacionales (Universidad Maimónides). Diploma en Derechos Económicos Sociales y Culturales (UNPSJB). Profesora Adjunta Ordinaria (Universidad Nacional de Luján -UNLu). Argentina. Correo electrónico: adporcelli@yahoo.com.ar

** Abogada-Escribana (UBA) Magíster en Ambiente Humano (UNLZ) Posgraduada en Derecho del Turismo (UBA). Profesora Asociada Ordinaria de Grado y Posgrado. Jefa de la División Derecho (Universidad Nacional de Luján- UNLu). Argentina.

Correo electrónico: info@anmart.com.ar

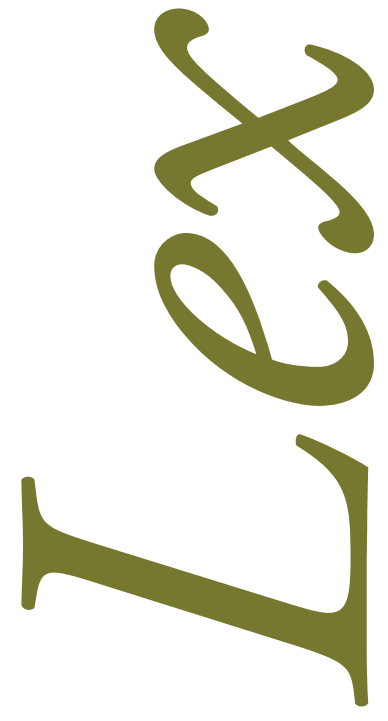




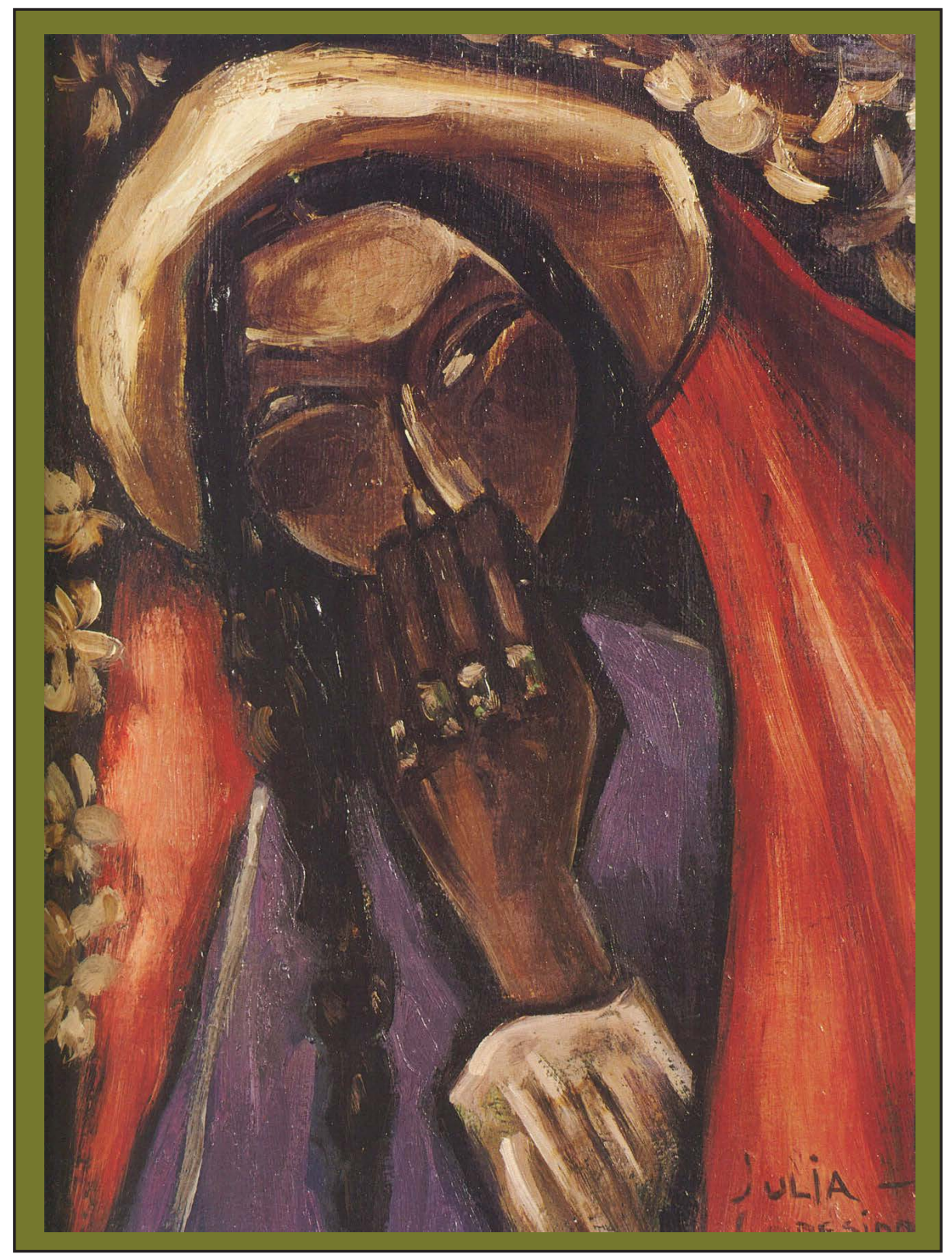

Mujer. Julia Codesido pintora peruana del indigenismo (Lima 1883-1879). 


\title{
RESUMEN
}

La pandemia por coronavirus aceleró un proceso ya en marcha en muchos países: la robotización de las fábricas y la coexistencia colaborativa entre los robots y los humanos, como en Asia. Esta situación excepcional pasará, pero los sistemas robóticos inteligentes se seguirán utilizando en las más variadas actividades y transformarán el mundo actual en una nueva realidad pospandemia. En este contexto, es que el presente artículo se planteó, como interrogante, si la inteligencia artificial aplicada a la robótica puede colaborar con los seres humanos en la reducción de la propagación del virus SARS-CoV-2. Para responder a tal cuestionamiento, el trabajo tiene por objeto ejemplificar la contribución de dichas tecnologías disruptivas en la actual crisis sanitaria y su reconstrucción posterior ya que los seres humanos deben adaptarse a una nueva normalidad. En cumplimiento de tal objetivo, la metodología se basó, primero en la descripción del marco conceptual utilizando el método científico descriptivo, específicamente la investigación bibliográfica, para examinar y diferenciar conceptos tales como derecho a la salud, inteligencia artificial y robótica. En segundo lugar, en el método de análisis sistemático de varios casos a los efectos de identificar y ejemplificar los diferentes aportes de la inteligencia artificial y la robótica para el bienestar de la salud mundial en el contexto de la pandemia y pospandemia. Una de las principales conclusiones a las que arribó el trabajo consistió en que la cooperación en el mismo ámbito de trabajo entre humanos y robots resultó indispensable para mantener la integridad de los trabajadores de la salud y de los grupos vulnerables más afectados por esta enfermedad. Sin embargo, a la vez, se planteó un nuevo desafío: regular estas nuevas tecnologías sin frenar los avances tecnológicos.

Palabras claves: inteligencia artificial, robótica, derecho a la salud, COVID-19.

\begin{abstract}
The coronavirus pandemic accelerated a process that was already underway in many countries: the robotization of factories and the collaborative coexistence between robots and humans, as in Asia. This exceptional situation will pass, but intelligent robotic systems will continue to be used in the most varied activities and will transform today's world into a new post-pandemic reality. It's in this context that this article raised, as a question, whether artificial intelligence applied to robotics can collaborate with humans in reducing the spread of the SARS-CoV-2 virus. To answer this question, the work aims to exemplify the contribution of these disruptive technologies in the current health crisis and its subsequent reconstruction, as human beings must adapt to a new normal. In compliance with this objective, the methodology was based, first on the description of the conceptual framework using the descriptive scientific method, specifically bibliographic research, to examine and differentiate concepts such as the right to health, artificial intelligence and robotics. Second, in the method of systematic analysis of several cases in order to identify and exemplify the different contributions of artificial intelligence and robotics for the well-being of global health in the context of the pandemic and post-pandemic. One of the main conclusions reached by the work was that cooperation in the same field of work between humans and robots was essential to maintain the integrity of health workers and vulnerable groups most affected by this disease. However, at the same time, a new challenge was posed: regulate these new technologies without slowing down technological advances.
\end{abstract}

Key words: artificial intelligence, robotics, right to health, COVID-19. 


\section{INTRODUCCIÓN}

La humanidad se encuentra transitando un cambio de paradigma social, económico, político y jurídico. Casi todos los aspectos de la vida cotidiana y laboral se digitalizan, hasta tal punto que, en el Foro Económico Mundial de Davos del 2016, Klaus Shwab popularizó el término Cuarta Revolución Industrial, título de su libro. En el mismo destacó que la Cuarta Revolución Industrial se basa en la convergencia de las tecnologías digitales, físicas y biológicas, desde Internet de las cosas, la nanotecnología, inteligencia artificial, robotización, impresiones $3 \mathrm{D}$ y vehículos autónomos para dar lugar a las Fábricas 4.0 o Fábricas Inteligentes, creando redes inteligentes que podrán controlarse a sí mismas ${ }^{1}$. Dos años antes, los profesores Brynjolfsson y McAfee, del Massachusetts Institute of Technology (MIT), se refirieron a este período como "la segunda era de las máquinas", ya que las capacidades y habilidades de las tecnologías digitales sorprendieron a la sociedad en su conjunto. Comenzaron a diagnosticar enfermedades, a entablar una conversación, a escribir prosa de alta calidad, y los robots iniciaron su recorrido por los almacenes y a conducir automóviles en forma automática. El mundo está en un punto de inflexión en que el efecto de estas tecnologías digitales se manifestará con una fuerza sin precedentes a través de la automatización y la creación de $\operatorname{cosas}^{2}$.

Sin embargo, Japón dio un paso más. En el año 2015 y en el marco del Quinto Plan Básico de Ciencia y Tecnología para 2016-2021 impulsado por la Oficina del Gabinete del primer ministro, Shinzo Abe, junto a la Federación de Empresas de Japón- Keidanren-fue el primer país en utilizar el término Sociedad 5.0, quién la presentó en la Feria de Hannover -Alemania-en el año 2017. Desde ese momento, el país nipón incorpora el término Quinta Revolución Industrial en paralelo con la Cuarta. Sus orígenes se encuentran en el contexto de la Iniciativa para la Revolución Robótica en Japón de 2015-2016, como respuesta a las estrategias desarrolladas en Europa, especialmente en Alemania con su Industria 4.0, y el Made in China $2025^{3}$.

1. Klauss Shwab. La Cuarta Revolución Industrial. (España: Debate, 2016), 9.

2. Erik Brynjolfsson y Andrew McAfee. The Second Machine Age. (New York/London: W.W. Norton \& Company, 2014), $1-3$.

3. Andrés Ortega. "Sociedad 5.0: el concepto japonés para una sociedad superinteligente". Estudios Internacionales y Estratégicos, ARI 10-2019, (España, Real Instituto Elcano, 2019) acceso el 3 de agosto de 2020, http://www.realinstitutoelcano.org/wps/portal/rielcano_es/contenido?WCM_GLOBAL_CONTEXT=/elcano/ elcano_es/zonas_es/economia+internacional/ari10-2019-ortega-sociedad-5-0-concepto-japones-sociedad-superinte ligente\#: :text=En 
La denominación Sociedad 5.0 deriva de la previa existencia de cuatro tipos de sociedades, a saber: la Sociedad 1.0 de caza y recolección; la Sociedad 2.0, agrícola; la Sociedad 3.0, industrial; y la Sociedad 4.0, de la información (que corresponde a la Cuarta Revolución Industrial). Según esta visión, ahora la humanidad está cursando la integración sofisticada del ciberespacio (la información) y del espacio físico (el llamado mundo real) que ha de conformar la Sociedad 5.0, centrada en los humanos, en las personas. Si la creación de conocimiento a partir de la información, en la Sociedad 4.0, la realizan los humanos, en la siguiente fase de la sociedad humana, la harán sobre todo las máquinas, a través de la inteligencia artificial, pero al servicio de las personas, las cuales podrán dedicarse a tareas creativas ${ }^{4}$.

El informe del 2019 de International Federation of Robotics intitulado "World Robotics 2019 - Industrial Robots and Service Robots" reportó que, durante el 2018, las instalaciones mundiales de robots industriales ascendieron a 422.271 unidades, lo que equivale a un aumento de un $6 \%$ con respecto al 2017, por un valor de 16.5 mil millones de dólares, sin contar software y periféricos ${ }^{5}$.

Sin embargo, en su último informe global, a fines del año 2020, las ventas de estas nuevas máquinas industriales, durante el 2019, si bien se mantuvieron en un nivel alto con 373.000 unidades a nivel mundial, registraron una reducción de $12 \%$ en comparación con 2018. Ello significa que sigue siendo el tercer volumen de ventas más alto jamás revelado. Durante el período entre el 2014 a 2019, las instalaciones anuales de robots aumentaron en un $85 \%$ en cinco ańos. La reciente desaceleración de las ventas en un $12 \%$ refleja los tiempos difíciles que han experimentado las dos principales industrias de clientes: la automotriz y la eléctrica/electrónica. De los datos se deduce que los cinco principales mercados globales de robots industriales son: China, Japón, Estado Unidos, la República de Corea y Alemania, los que suman el 73\% de las instalaciones mundiales. Asia, incluida Australia y Nueva Zelanda, se constituye en el mercado más fuerte para los robots industriales. Particularmente China, aumentó un 21\% y alcanzó aproximadamente 783.000 unidades en 2019. Japón ocupa el segundo lugar con aproximadamente 355.000 unidades, un $12 \%$ más. India, con un nuevo récord de aproximadamente 26,300 unidades, aumentó un 15\%, y en cinco años, duplicó el número de robots industriales que operan en las fábricas del país.

Por su parte, Europa alcanzó un stock operativo de 580.000 unidades en 2019, registrando un aumento del $7 \%$. Alemania sigue siendo el principal usuario con un stock operativo de aproximadamente 221.500 unidades; esto es aproximadamente tres veces el de Italia (74.400 unidades), cinco veces el de Francia (42.000 unidades) y unas diez veces el del Reino Unido (21.700 unidades). Las ventas de robots muestran una imagen diferenciada para los mercados más grandes de la Unión Europea ya que se instalaron alrededor de 20.500 robots en Alemania. En Francia, las ventas aumentaron un 15\%, en

4. Keidanren, Society 5.0. Co-creating the future. (2018) p. 9, acceso el 18 de diciembre de 2020, desde https://www.keidanren.or.jp/en/policy/2018/095.html

5. International Federation of Robotics, World Robotics 2019 - Industrial Robots and Service Robots. (Frankfurt: International Federation of Robotics, 2019), 13. 
Italia un 13\% y en los Países Bajos un 8\%, pero el Reino Unido se mantiene en un nivel bajo porque se ralentizaron en un $16 \%$. Las 2.000 unidades instaladas en dicho país son unas diez veces menos que los envíos en Alemania (20.500 unidades), unas cinco veces menos que en Italia (11.100 unidades) y unas tres veces menos que en Francia (6.700 unidades).

En América, Estados Unidos es el mayor usuario de robots industriales, alcanzando un nuevo récord de stock operativo de aproximadamente 293.200 unidades, registrando un aumento del 7\%. México ocupa el segundo lugar con 40,300 unidades, lo que representa una ventaja del 11\%, seguido de Canadá con aproximadamente 28,600 unidades, vale decir un 2\% más. Las nuevas instalaciones se desaceleraron en un 17\% durante el 2019 en comparación con 2018. En cuanto a las ventas, en Estados Unidos se mantienen en un nivel muy alto, con 33,300 unidades enviadas. México ocupa el segundo lugar con casi 4,600 unidades adquiridas, con una desaceleración del $20 \%$, mientras que las ventas en Canadá registraron un nuevo récord de alrededor de 3.600 unidades enviadas. El país con mayor stock operativo de América del Sur es Brasil, con casi 15.300 unidades, lo que significa un $8 \%$ más. Si bien las ventas se desaceleraron en un $17 \%$ comparado con el 2018 , sigue siendo uno de los mejores resultados de la historia, con alrededor de 1.800 instalaciones, solo superado por envíos récord en 2018.

Específicamente, la industria automotriz sigue siendo el mayor rubro en los que se utilizan estas máquinas, con un total del 28\% y en el período que va entre 2014 a 2019, dicha industria creció un promedio del 2\% por ańo. Desde 2010, las inversiones en modernización de la producción de automóviles han impulsado la demanda de robots.

Las instalaciones en la industria de electricidad / electrónica (incluyendo computadoras, equipos de radio, TV y demás dispositivos creció, en promedio anual, un 24\% desde 2013 a 2018. Sin embargo, desde 2018, la demanda mundial de dispositivos y componentes electrónicos sufrió una merma sustancial. Esta industria probablemente es la más afectada por la guerra comercial entre China y los estados Unidos ya que los países asiáticos son líderes en la fabricación de productos electrónicos y componentes. En 2019, las instalaciones de robots en esta industria disminuyeron un 17\%. Es necesario aclarar que este promedio global solo incluye aquellos países que tienen un stock operativo relevante. Por lo tanto, los países con baja densidad de robots son sistemáticamente excluidos.

En síntesis, la industria automotriz es la que utiliza en mayor número a los robots, con un $28 \%$; seguida por la electricidad / electrónica, con un $24 \%$; la metal/mecánica, con $12 \%$; plástico y productos químicos, con un 5\% y finalmente alimentos y bebidas, con un 3\%. En Asia, desde 2014 e impulsado por el gran volumen de instalaciones de robots, la densidad promedio aumentó en un 18\% y, en particular, en 2019 se establecieron 118 unidades por cada 10.000 empleados. Mientras que, en Europa, desde 2014, creció solo un 6\% y ascendió a 114 unidades por cada 10,000 empleados en 2019. Y en las Américas, fue 103 robots por cada 10.000 empleados. 
La adopción de la colaboración entre humanos y robots, los denominados cobots, va en aumento. La Federación Internacional de Robots detectó que las instalaciones de cobots crecieron un 11\%. Este desempeño dinámico de las ventas contrasta con la tendencia general de los robots industriales tradicionales en 2019. A medida que más proveedores ofrecen robots colaborativos y la gama de aplicaciones aumenta, la cuota de mercado alcanzó el 4,8\% del total de 373.000 robots industriales instalados en $2019^{6}$.

Respecto a los robots de servicios, la International Federation of Robotics, indica que abarcan un amplio campo de aplicaciones, la mayoría con diseños únicos y diferentes grados de automatización. Por lo tanto, dicha industria es más diversa que la de los industriales y el número total de autómatas de servicios profesionales vendidos en 2019 aumentó un 32\%. Los mercados de estos tipos de robots no parecen estar afectados por la pandemia de Covid-19. De hecho, ha impulsado el mercado de soluciones desinfectantes robóticas y creó una demanda adicional para la logística robótica en almacenes, fábricas y para la entrega de mercaderías a domicilio. Es que las soluciones robóticas apoyan el distanciamiento social y no se encuentran afectados por el cierre de fronteras. Las aplicaciones robóticas en logística aumentaron en un 42\% en 2019 y la facturación se incrementó en un $110 \%$.

Especial mención obtuvo la comercialización de los robots en aplicaciones médicas, que se encuentran entre los más caros del mercado, cuyas ventas se incrementaron en un $28 \%$ en 2019, representando el 47\% de las ventas totales de unidades. Las aplicaciones médicas más importantes fueron en cirugía asistida por robot o los sistemas de terapia y rehabilitación.

Por otro lado, la utilización de los robots en las actividades agropecuarias creció un 3\% en términos de facturación y en un $8 \%$ en términos de unidades. Si bien se han establecido soluciones robóticas en la producción lechera, las aplicaciones agrícolas como la recolección de frutas constituye un desafío para la robótica tanto a nivel tecnológico como por económico por los costos bastante bajos del trabajo humano. Sin embargo, la pandemia de Covid-19 podría modificar esta situación y ofrecer una excelente oportunidad para los proveedores de este tipo de robots ya que las restricciones de viaje están provocando escasez de mano de obra en la temporada de cosecha.

En las áreas de mantenimiento e inspección, las soluciones robóticas han experimentado un tremendo aumento en los últimos años. La facturación se incrementó un 131\% en 2019. Los robots también se vuelven más comunes en entornos públicos ya que, en 2019, creció un 44\% y la facturación en un $42 \%$. De la misma forma, el mercado de los robots de limpieza profesionales se beneficiará por el aumento de los requisitos de higiene en la pandemia de Covid-19.

Otro rubro donde se evidencia un crecimiento es en las ventas unitarias de los exoesqueletos humanos motorizados, las que aumentaron un $26 \%$ en 2019 , pero esto sigue siendo un rendimiento inferior

6. International Federation of Robotics, Executive Summary World Robotics 2020 - Industrial Robots, (Frankfurt: International Federation of Robotics, 2020), 13-16. 
en comparación con su potencial y la amplia gama de aplicaciones que tiene. Los robots de servicio profesional, en 2019 se incrementaron en un $32 \%$ con 173.000 unidades vendidas y se proyecta para el 2023 un total de 537,000 unidades, lo que significaría un 31\% En caso de servicio para tareas domésticas, en 2019, se vendieron 18,6 millones de unidades, registrando un aumento del $40 \%$ y se prevé, para el 2023, 48,6 millones de unidades, más del 31\%. En cuanto a los de servicio para entretenimiento, en el 2019, se adquirieron 4,6 millones de unidades, incrementándose en un 13\%, y para el 2023 se programa 6,7 millones de unidades vendidas, es decir un 10\% más 7 .

A nivel mundial, el COVID-19 tendrá un fuerte impacto en 2021, pero también ofrece una oportunidad para la modernización y digitalización de la producción en el camino hacia la recuperación. A largo plazo, los beneficios y los principales incentivos de aumentar las instalaciones robóticas siguen siendo los mismos: la rápida producción y la entrega de productos personalizados a precios competitivos. La automatización permite a los fabricantes mantener la producción en las economías desarrolladas, o reubicarla, sin sacrificar la rentabilidad. La gama de robots industriales continúa expandiéndose, desde robots tradicionales capaces de manejar todas las cargas útiles de manera rápida y precisa hasta los nuevos robots colaborativos que trabajan de manera segura junto con los humanos, completamente integrados en los bancos de trabajo.

La Organización Mundial de la Salud, reconoció que la inteligencia artificial y la robótica se constituyen como herramientas fundamentales para lograr los Objetivos de los Tres Mil Millones, a saber, que 1000 millones más de personas logren cobertura sanitaria universal, 1000 millones más de personas obtengan una mejor protección frente a las emergencias sanitarias y que 1000 millones más de personas mejoren su salud y bienestar ${ }^{8}$. Por supuesto que en el campo sanitario es necesario resguardar por lo menos dos aspectos. El primero, que los robots no reemplazan al profesional de la medicina, son colaboradores y siempre deben estar bajo supervisión y control humano. Y el segundo que, al tratarse de datos sensibles, merecen especial protección y cuidado para evitar replicar en los algoritmos algún tipo de discriminación o sesgo social preexistente.

En este contexto, la Organización Mundial de la Salud declaró la pandemia de enfermedad por coronavirus de 2019-2020 (COVID-19). En julio de 2020 tuvo su epicentro en América Latina y en octubre del mismo año manifestó un rebrote alarmante en Europa ${ }^{9}$. En la actualidad, ya se cuenta casi 106 millones de casos y más de 2 millones de muertos en todo el planeta. La oficina europea de la

7. International Federation of Robotics, Executive Summary World Robotics 2020 - Service Robots, (Frankfurt: International Federation of Robotics, 2020), 11-12.

8. Organización Mundial de la Salud, "La OMS presenta reformas de gran envergadura para alcanzar las metas de los "tres mil millones", (6 de marzo de 2019), acceso el 10 de noviembre de 2020, https://www.who.int/es/news-room/ detail/06-03-2019-who-unveils-sweeping-reforms-in-drive-towards-triple-billion-targets

9. Organización Mundial de la Salud, "Brote de enfermedad por coronavirus (COVID-19)", (2020) acceso el 15 de noviembre de 2020, https://www.who.int/es/emergencies/diseases/novel-coronavirus-2019?gclid=CjwKCAjw_D3BRBIEiwAjVMy7LoQ-sw-m1weY0UFQ2vweql1FItqwPSLkmiE4_cdEPuF-kgiiAevVBoC7RcQAvD_BwE. 
Organización Mundial de la Salud alertó sobre la existencia de elevado riesgo, en los primeros meses de 2021, de un resurgimiento de la pandemia. A partir del 16 de diciembre y hasta el 10 de enero de 2020, Alemania estableció en un nuevo confinamiento social ${ }^{10}$. En Londres, hoteles, restaurantes y locales de ocio volvieron a cerrar y la justicia de Río de Janeiro, ordenó el cierre de playas, hoteles y restaurantes en el paradisíaco balneario de Buzios y dio 72 horas para que los turistas abandonen la ciudad. Y la situación se complicó aún más, ya que en el Reino Unido se detectó una nueva cepa del COVID y enfrentó este nuevo contexto virtualmente aislado por la prohibición de vuelos desde y hasta dicho país, medida a la que además de Francia se sumó una larga lista de países, entre ellos España, Portugal, Canadá, India, Hong Kong, Rusia, Marruecos, Suiza, Polonia, Argentina, Paraguay, Perú, Colombia y Chile e Israel ${ }^{11}$.

La cepa mutante ya está provocando una segunda/tercera ola en la Unión Europea. En realidad, hay continuas mutaciones silenciosas que seguirán viniendo. Algunas pueden afectar a la eficacia de las vacunas que ya están siendo administradas. Pero a medida que la vacuna vaya arrinconando al virus SARS-CoV-2, éste reaccionará. Dicha reacción será en forma de cambios y mutaciones más profundas que se producirán a lo largo del tiempo, haciendo que las vacunas dejen de ser efectivas. Pero este proceso no será rápido, y se pueden desarrollar vacunas apropiadas ante las nuevas cepas que mutan. En cierto modo, pasará como con la gripe estacional: cada temporada se prepara una nueva vacuna que se distribuye por todo el mundo ${ }^{12}$.

En el presente artículo ${ }^{13}$ se planteó, como interrogante, si la inteligencia artificial aplicada a la robótica puede colaborar con los seres humanos en la reducción de la propagación del virus SARS-CoV-2. Para responder a tal cuestionamiento, el trabajo tiene por objeto ejemplificar la contribución de dichas nuevas tecnologías en la actual crisis sanitaria que padece la humanidad derivada de la pandemia y su reconstrucción pospandemia ya que los seres humanos deben adaptarse a una nueva normalidad. En cumplimiento de tal objetivo, la metodología se basó, primero en la descripción del marco conceptual utilizando el método científico descriptivo, específicamente la investigación bibliográfica, para examinar y diferenciar conceptos tales como derecho a la salud, inteligencia artificial y robótica. En segundo

10. Ángela Gómez, "Alemania anuncia "un nuevo confinamiento duro" ante el aumento de los contagios por COVID-19", France 24, (13 de dic. de 2020), acceso el 18 de diciembre de 2020, https://www.france24.com/es/europa/20201213-covid19hoy-alemania-cierra-de-nuevo-la-navidad-ser\%C3\%A1-enaislamiento.

11. Véase: "Reino Unido, virtualmente aislado por el brote de una nueva cepa más contagiosa" Telam, (21 de dic. de 2020), acceso el 22 de diciembre de 2020, https://www.telam.com.ar/notas/202012/539175-reunion-crisis-reinounido-frontera-francia.html

12. Santiago de Quiroga, "2021: ¿Comienza la era de los coronavirus?”, Gaceta Médica (2020) acceso el 5 de febrero de 2021, https:/gacetamedica.com/opinion/la-contra/2021-comienza-la-era-de-los-coronavirus/

13. Este artículo deriva del Proyecto de Investigación aprobado en septiembre de 2020 intitulado "Dilemas éticos, sociales y ambientales acerca de las aplicaciones de Internet de las Cosas, Inteligencia Artificial y Robótica. Su necesaria regulación ética y jurídica” en la Universidad Nacional de Luján-Argentina 
lugar, en el método de análisis sistemático de casos a los efectos de identificar y ejemplificar los diferentes aportes de la inteligencia artificial y la robótica para el bienestar de la salud mundial en el contexto de la pandemia y pospandemia. Una de las principales conclusiones a las que arribó el trabajo consistió en que la cooperación en el mismo ámbito de trabajo entre humanos y robots resultó indispensable para mantener la integridad de los trabajadores de la salud y de los grupos vulnerables más afectados por esta enfermedad. Sin embargo, a la vez, se planteó un nuevo desafío: regular estas nuevas tecnologías sin frenar los avances tecnológicos.

\section{MARCO CONCEPTUAL}

\section{1.- Derecho a la salud}

El derecho a la salud es parte fundamental de los derechos humanos. El derecho a disfrutar del nivel más alto posible de salud física y mental no es nuevo y en el plano internacional se proclamó por primera vez en la Constitución de la Organización Mundial de la Salud de 1946, en cuyo preámbulo se define la salud como "un estado de completo bienestar físico, mental y social, y no solamente la ausencia de afecciones y enfermedades". En dicho instrumento internacional se afirma que "el goce del grado máximo de salud que se pueda lograr es uno de los derechos fundamentales de todo ser humano, sin distinción de raza, religión, ideología política o condición económica o social”" ${ }^{14}$.

Por su parte, en la Carta de Ottawa para la Promoción de la Salud, dicha organización internacional señaló como prerrequisitos para la salud, a la paz, la educación, la vivienda, adecuados recursos económicos y alimenticios, un ecosistema estable, la justicia social y la equidad ${ }^{15}$. El reconocimiento de estos prerrequisitos pone de manifiesto la estrecha relación que existe entre las condiciones sociales y económicas, el entorno físico, los estilos de vida individuales y la salud. Estos vínculos constituyen la clave para una comprensión holística de este derecho que es primordial en la definición de la promoción de la salud. Hoy en día, su dimensión espiritual goza de un reconocimiento cada vez mayor y todas las personas deben tener acceso a los recursos sanitarios básicos. Por tanto, el derecho a la salud es un derecho inclusivo. Frecuentemente se lo asocia con el acceso a la atención sanitaria y con la construcción de hospitales, lo cual es cierto, pero el derecho a la salud es algo más. Comprende un amplio conjunto de factores que pueden contribuir a una vida sana.

El Comité de Derechos Económicos, Sociales y Culturales, en su Observación General No 14 del año 2000 sobre el derecho a la salud, enumera como "factores determinantes básicos de la salud" los siguientes: a) agua potable y condiciones sanitarias adecuadas; b) alimentos aptos para el consumo; c) nutrición y vivienda adecuadas; d) condiciones de trabajo y un medio ambiente salubres; e) educación e información sobre cuestiones relacionadas con la salud y d) igualdad de género.

14. Organización Mundial de la Salud, Constitución de la Organización Mundial de la Salud (Nueva York: OMS, 1946), 1 , acceso el 1 de febrero de 2021,

https://apps.who.int/gb/bd/PDF/bd48/basic-documents-48th-edition-sp.pdf?ua=1\#page=7

15. Organización Mundial de la Salud, Carta de Ottawa para la Promoción de la Salud (Ottawa: OMS, 1986) 1. 
En cuanto a los elementos de este derecho, en el precitado documento se mencionan: a) disponibilidad: cada Estado deberá contar con un número suficiente de establecimientos, bienes y servicios públicos de salud y programas; b) accesibilidad para todos, sin discriminación alguna. La misma comprende la accesibilidad física, vale decir que los establecimientos deben estar al alcance geográfico de todos los sectores de la población; la económica, que importa que los establecimientos, bienes y servicios de salud deberán estar al alcance de todos. Y el acceso a la información, que incluye el derecho a solicitar, recibir y difundir información acerca de esta derecho; c) aceptabilidad: todos los establecimientos, bienes y servicios de salud deberán ser respetuosos de la ética médica y de la cultura de las personas, minorías, pueblos y comunidades; d) calidad: los establecimientos, bienes y servicios deberán ser apropiados desde el punto de vista científico y médico; e) no discriminación, en especial para los sectores más vulnerables y desprotegidos de la población ${ }^{16}$ (Comité de Derechos Económicos, Sociales y Culturales, 2000).

El derecho a la salud comprende algunos derechos y libertades, por ejemplo: a no ser sometido a tratamiento médico sin el propio consentimiento; a un conocimiento informado y a negarse a determinadas terapias; a un sistema de protección de la salud que brinde a todos iguales oportunidades; a la prevención y el tratamiento de las enfermedades y la lucha contra ellas; al acceso a medicamentos esenciales; a la salud materna, infantil y reproductiva; al acceso a la educación y a la información sobre cuestiones relacionadas con la salud. A su vez, la no discriminación es un principio fundamental de los derechos humanos y es decisiva para el disfrute del derecho al más alto nivel posible de salud. Por lo cual, los Estados tienen la obligación primordial de proteger y promover los derechos humanos y el derecho a la salud entre ellos. Dicha obligación consiste en una realización progresiva, por lo que los Estados deben demostrar al menos que están haciendo todo lo posible, dentro de los límites de los recursos disponibles. Se entiende por este último tanto los existentes en el Estado, así como los disponibles en la comunidad internacional. Estos últimos no son un sustitutivo de las obligaciones nacionales, sino que son aplicables, en particular, cuando un Estado no puede hacer efectivos tales derechos por sí mismo y requiere la asistencia de otros Estados para ello ${ }^{17}$.

A este derecho se refieren varios de los Tratados Internacionales sobre Derechos Humanos, a saber: el Pacto Internacional de Derechos Económicos, Sociales y Culturales - artículo 12-, la Declaración Universal de Derechos Humanos- artículos 3, 22 y 25-, la Declaración Americana de los Derechos y Deberes del Hombre - artículo XI-, la Convención Internacional sobre la Eliminación de todas las Formas de Discriminación Racial -artículo 5- la Convención sobre la Eliminación de Todas las Formas de Discriminación contra la Mujer -artículos 11 1) f) y 12-, la Convención sobre los Derechos del Niño - artículo 24-, la Convención Americana sobre Derechos Humanos, la Convención Internacional

16. Comité de Derechos Económicos, Sociales y Culturales. Observación General No 14: "El derecho al disfrute del más alto nivel posible de salud" (artículo 12 del Pacto Internacional de Derechos Económicos, Sociales y Culturales) (E/C.12/2000/4, 2000) 4-6.

17. Oficina del Alto Comisionado de las Naciones Unidas para los Derechos Humanos y Organización Mundial de la Salud, El derecho a la salud. Folleto Informativo $N^{\circ} 31$, (Nueva York: Oficina del Alto Comisionado de las Naciones Unidas para los Derechos Humanos, 2008), 37-40. 
sobre la Protección de los Derechos de todos los Trabajadores Migratorios y de sus Familiares- artículos 28, 43 e) y 45 c) -, la Convención sobre los derechos de las personas con discapacidad- artículo 25- y el Protocolo Adicional a la Convención Americana sobre Derechos Humanos en la Esfera de los Derechos Económicos, Sociales y Culturales, denominado Protocolo de San Salvador (1988). La Declaración del Milenio comprometió a los dirigentes mundiales a erradicar la pobreza extrema y el hambre, mejorar la salud materna y combatir el VIH/SIDA, el paludismo y otras enfermedades. Finalmente, entre los Objetivos de Desarrollo Sostenible del 2015, el ODS 3 se refiere a que garantizar una vida sana y promover el bienestar en todas las edades es esencial para el desarrollo sostenible.

\section{2.- Inteligencia Artificial y Robótica}

A continuación, se desarrollarán los conceptos de inteligencia artificial y robótica, destacando que, si bien ambas son tecnologías disruptivas, no son sinónimos.

En primer lugar, el Diccionario Enciclopédico Espasa (1993) define al término inteligencia, conforme sus diferentes acepciones, de la siguiente manera: "2. Facultad de conocer. 3. Conocimiento, comprensión, acto de entender.4. Habilidad, destreza y experiencia. Inteligencia artificial: conjunto de técnicas que, mediante el empleo de ordenadores, permite resolver problemas cuya solución corresponde a la inteligencia humana." ${ }^{18}$.

Pérez Luño considera que, en occidente, se pueden diferenciar tres grandes acepciones de dicho vocablo, a saber: a) como práctica: vale decir como virtud para discernir y actuar racionalmente; b) como saber teórico: que permite aprehender y representar formalmente la realidad y c) como racionalidad instrumental, que alude a la idoneidad de los medios requeridos para la obtención de determinados objetivos. Para expresar estas últimas dos acepciones, actualmente se distingue entre inteligencia epistemológica, que permite la representación formal del mundo y la solución de los problemas y la heurística, que en función de informaciones y conocimientos adquiridos privados resuelve problemas y decide los medios o instrumentos adecuados para el logro de objetivos. El mencionado autor continúa advirtiendo que la noción de inteligencia tanto en su sentido epistemológico como heurístico, resulta predicable respecto a determinados tipos de software que reproducen procesos mentales. Sin embargo, no implica que la inteligencia humana pueda ser íntegramente suplantada por las computadoras ya que existe un sector de la misma, el mencionado en primer lugar o práctico, en el que la posibilidad de aplicar la inteligencia artificial resulta más problemática. Se trata de actividades y valoraciones que los seres humanos llevan a cabo a través de su estructura biológica y psicológica en función de experiencias sociales y culturales ${ }^{19}$.

Actualmente, no se ha consensuado en forma universal una única definición para esta última termi-

18. Espasa Calpe, Diccionario Enciclopédico Espasa. Inteligencia, 3, (Madrid: Espasa Calpe, 1993), 911.

19. Antonio Pérez Luño "Sistemas expertos jurídicos: premisas para un balance”, en Calculemos... Matemáticas y libertad, coords. Lorenzo Peña, Javier de Lorenzo Martínez y Javier Echeverría Ezponda. (España: Trotta, 1996), $274-275$. 
nología, como también existe una confusión respecto a que técnicas se consideran inteligencia artificial o cuáles corresponden a tareas automatizas. El término inteligencia artificial fue acuńado en 1956 por el científico John McCarthy, cuando, junto con Minsky, Rochester y Shannon, iniciaron el proyecto de investigación "inteligencia artificial”, en Dartmouth College en los Estados Unidos. Inicialmente, su objetivo era que la inteligencia humana pudiera ser descrita de forma tan precisa que una máquina fuera capaz de simularla. McCarthy la definió como "la ciencia y la ingeniería de hacer máquinas inteligentes, especialmente programas informáticos inteligentes. Está relacionada con la tarea similar de usar computadoras para comprender la inteligencia humana, pero la IA no tiene que limitarse a métodos que son biológicamente observables"20.

También se la conceptualiza como "una disciplina informática encargada de realizar programas de computadora, cuyo resultado final (producto de reglas de transformación y composición), de ser imputado a un humano implicaría inteligencia" ${ }^{21}$.

Otras definiciones se centran en la posibilidad de readaptarse y modificar su conducta en base a lo aprehendido, por ejemplo, como "[l] a capacidad de un sistema para interpretar correctamente datos externos, para aprender de dichos datos y emplear esos conocimientos para lograr tareas y metas concretas a través de la adaptación flexible"22.

Con el transcurso del tiempo y a medida que los avances tecnológicos fueron perfeccionándose hacia áreas de conocimiento específicos, el concepto de inteligencia artificial fue evolucionando hacia una combinación entre el reconocimiento de imagen, el procesamiento de lenguaje, las redes neuronales y las acciones orientadas a un único objetivo. La Comisión Europea considera que:

El término «inteligencia artificial» (IA) se aplica a los sistemas que manifiestan un comportamiento inteligente, pues son capaces de analizar su entorno y pasar a la acción -con cierto grado de autonomía- con el fin de alcanzar objetivos específicos. Los sistemas basados en la IA pueden consistir simplemente en un programa informático (p. ej. asistentes de voz, programas de análisis de imágenes, motores de búsqueda, sistemas de reconocimiento facial y de voz), pero la IA también puede estar incorporada en dispositivos de hardware (p. ej. robots avanzados, automóviles autónomos, drones o aplicaciones del internet de las (cosas) ${ }^{23}$.

En esta definición es de destacar que la inteligencia artificial no es sinónimo de robots, ya que pueden encontrase robots inteligentes siempre que tengan incorporado ese sistema o software específico,

20. John McCarthy, "What Is Artificial Intelligence” Universidad de Stanford. Sección Basic Questions, (2007),1, acceso el 8 de febrero de 2020, http://www-formal.stanford.edu/jmc/whatisai/node1.html] el 08.02.2020.

21. Enrique Cáceres Nieto, "Constructivismo jurídico e inteligencia artificial en el proyecto CONACYT-IIJ-CCADET-TSJT”. Revista El Siete. Revista Jurídica Estudiantil Departamento de Derecho Universidad de Sonora 2, 7, México: Universidad de Sonora (2006): 2-16.

22. Andeas Kaplan y Michael Haenlein, "Siri, Siri in my Hand, who's the Fairest in the Land? On the Interpretations, Illustrations and Implications of Artificial Intelligence", Business Horizons 62, 1 (2018) 15-25.

23. Comisión Europea, "Comunicación de la Comisión al Parlamento Europeo, al Comité Económico y Social Europeo y al Comité de las Regiones: Inteligencia Artificial para Europa”, (COM, 237 final, 25 de abril de 2018), 1. 
pero también existen máquinas que realizan tareas automáticas que no configuran inteligencia. De la misma forma, la inteligencia artificial no siempre se encuentra materializada en un robot, es una forma específica de programación.

Cuando se menciona la palabra "inteligente" se incurre en el equívoco que el sistema es capaz de realizar cualquier tarea que un ser humano inteligente puede realizar, desde las actividades más simples hasta las más complejas. Nada más alejado de la realidad ya que la inteligencia artificial es limitada. Ser capaz de resolver un problema, no significa tener la capacidad de resolver otro diferente. A ello debe sumarse lo que se conoce como el "olvido catastrófico", consistente en la dificultad de enseńar nuevas habilidades para realizar nuevas tareas sin perder las funciones previamente aprendidas ${ }^{24}$. Ahora bien, las máquinas, para poder aprender, necesitan ser alimentadas con datos sobre los usuarios y sobre el entorno general que las rodea. Como no pueden percibir a través de los sentidos, toda la información necesaria para operar es ingresada por los matemáticos por medio de los paquetes de datos en forma de algoritmos. Dichos algoritmos les permiten a las máquinas identificar y clasificar la información mediante los métodos de "machine learning"- aprendizaje automático y de "deep learning"- aprendizaje profundo, más sofisticado.

El primero alimenta a la máquina con altas dosis de datos predefinidos y categorizados por el humano para que los reconozca en el futuro. De esta manera, las máquinas son entrenadas para aprender a ejecutar diferentes tareas de forma autónoma. Luego, cuando son expuestas a nuevos datos, ellas se adaptan a partir de los cálculos anteriores y los patrones se moldean para ofrecer respuestas confiables. En lugar de programar reglas en una computadora y esperar el resultado, con machine learning, la máquina aprenderá esas reglas por cuenta propia.

El segundo, más preciso, es la parte del aprendizaje automático que, por medio de algoritmos de alto nivel, imita la red neuronal del cerebro humano. Para llegar al nivel de aprendizaje profundo más avanzado, los datos son sometidos a varias capas de procesamiento no lineares que simulan la forma de pensar de las neuronas y se basa en la idea del aprendizaje exclusivamente desde el entrenamiento. Es así que, el programador, en lugar de enseñarle al sistema una lista enorme de reglas para resolver un problema, le proporciona directamente un modelo para que pueda, mediante ejemplos, realizar la evaluación.

De forma simplificada en deep learning se construyen algoritmos complejos mediante el empleo de las capas internas (la denominada "caja negra") de la red neuronal. Cada capa procesa la información y arroja un resultado que se revela en porcentaje. Por ejemplo, se le solicita al sistema que busque en una foto un gato, concluirá que dicha imagen es en un $78 \%$ de probabilidad un gato y en un $22 \%$ no lo es. La segunda capa que analice la imagen combinará el resultado obtenido por la primera capa con su propio juicio. De tal forma que la ponderación se modificará y se trasladará a la tercera capa, que también usará este dato para sacar su propia conclusión. Así sucesivamente porque las redes neuronales tradicionales solo contienen dos o tres capas ocultas, mientras que las redes profundas pueden tener hasta 150 capas, de ahí la denominación de profundo. Es de destacar que machine learning comenzó en

24. Ramón López de Mántaras, citado en: Esther Paniagua, Future Trend Forum. Inteligencia Artificial. (Madrid: Fundación Innovación Bankinter, 2019), 5. 
los años 80 mientras que deep learning recién empezó a desarrollarse en el año 2010, con el surgimiento de computadoras poderosas y el aumento de los datos accesibles. Actualmente se utiliza en programas tales como: traductores inteligentes, reconocimiento de imágenes, asistentes de voz con capacidad de interpretación semántica. Sin embargo, el gran problema que presenta esta técnica de aprendizaje es el fenómeno de la caja negra ya que es imposible conocer lo que sucede en el interior de las capas intermedias de las redes neuronales para justificar el resultado o decisión tomada. Es así que, solo se conoce la entrada y la salida del mismo, las capas intermedias son tan opacas como el cerebro humano ${ }^{25}$.

En base a lo expresado ut supra, en la actualidad, se diferencian dos métodos de inteligencia artificial: la débil y la fuerte (Searle,1980). El primero se centra únicamente en tareas rutinarias y técnicas, sólo se aplica a un tipo específico de problemas y sin capacidad de pensar. En cambio, el segundo implicaría que una computadora no simula una mente, sino que es "una mente" dotada de una inteligencia igual o incluso superior a la humana. Supone capacidad de abstracción, reflexión, habilidades sociales, afán creativo e improvisación, con capacidad de autoprogramación y de adaptación a nuevos escenarios ${ }^{26}$. Actualmente no existen ejemplos de esta última, quedando relegada al campo de la ciencia ficción.

Arend Hintze, profesor de Biología Integrada y Ciencias de la Computación de la Universidad de la Michigan, clasifica la inteligencia artificial en cuatro tipos, según el nivel de complejidad:

a) Máquinas reactivas, la expresión más básica de la inteligencia artificial: se asemejan al funcionamiento tradicional de una computadora al que se le proporciona una serie de datos y debe procesarlos para obtener un resultado satisfactorio.

b) Inteligencia artificial con memoria limitada: su nombre hace referencia a su capacidad para registrar experiencias pasadas para aplicarlas en sus decisiones. Se utilizan en aplicaciones tan variadas como la industria automotriz, la inteligencia artificial integrada en dispositivos móviles o los asistentes por voz. Estos sistemas utilizan el aprendizaje automático para, en base a unos conocimientos base, añadir nueva información a su base de datos para mejorar su funcionamiento.

c) Máquinas basadas en la teoría de la mente: la teoría de la mente es un principio psicológico en el que se sostiene que todos los seres vivos pueden tener emociones y pensamientos que afectan tanto a su comportamiento como a las decisiones que tomen. Esta capacidad de procesar emociones y exponerlas al entorno es uno de los grandes pilares en los que se basan las sociedades humanas, por lo que supone el primer paso en la integración de la inteligencia artificial como parte de esa sociedad y no como un mero dispositivo. Este planteamiento base supone un funcionamiento mucho más humano en el desarrollo de procesos de inteligencia artificial ya que el agente de inteligencia artificial debe ser capaz de comprender las emociones de su interlocutor y de mostrar las propias. Por el momento esta categoría

25. Mariano Torres, Derechos y desafíos de la Inteligencia Artificial (Buenos Aires: CyTA, 2019) 17, 18.

26. John Searle, “Minds, brains, and programs". Behavioral and Brain Science 3, 3 (1980) 417- 424. 
se encuentra solo en fase experimental, pero ya existen procesos capaces de detectar estados de ánimo en las personas por los gestos de su cara, los matices de la voz, gritos, insultos y otros indicadores de conducta humana.

d) Inteligencia artificial con conciencia de sí misma: esta fase se encuentra en un estado meramente teórico. Es el nivel máximo ya que sería el más próximo a los seres vivos. Las máquinas comprenderían sus sentimientos y son capaces de verse a sí mismas con perspectiva en su entorno, de manera interna y siento capaces de predecir comportamientos y sentimientos ajenos ${ }^{27}$.

Stuart Russell y Peter Norvig diferencian cuatro enfoques de inteligencia artificial: a) sistemas que piensan como humanos, que son capaces de tomar decisiones autónomas y resolver problemas, y también tienen capacidad de aprendizaje; b) sistemas que actúan como humanos e imitan su comportamiento; c) sistemas que piensan racionalmente, capaces de inferir una solución a un caso a partir de una información sobre un contexto dado y d) sistemas que emulan la forma racional del comportamiento humano, como los sistemas inteligentes o expertos ${ }^{28}$.

Si bien excede el objeto del presente artículo, no se puede explicar la inteligencia artificial sin mencionar los aportes de Noam Chomsky al lenguaje computacional, al proponer la "gramática generativa", una teoría del lenguaje inspirada en los lenguajes artificiales de la lógica y las matemáticas. Según este prestigioso académico, la facultad de idiomas es parte del organismo. En la mente humana ya existe algo innato que será el germen del lenguaje, por ello, los humanos adquieren un sistema cognitivo lingüístico. De acuerdo con este principio, el lenguaje puede ser transmitido genéticamente y los seres humanos poseen una estructura lingüística similar independientemente de sus diferencias sociales y culturales $^{29}$. Así, Chomsky estableció cuatro tipos de lenguaje con sus correspondientes gramáticas y máquinas asociadas en forma jerárquica, conocido como la Jerarquía de Chomsky. De esta manera, influyó en la lingüística computacional, en los sistemas expertos basados en sistemas de diálogos de pregunta y respuesta, con una base de datos primitiva, un motor de búsqueda y resolución de problemas mediante el lenguaje natural que faculta a las máquinas a comunicarse con las personas. Es más, en la actualidad la inteligencia artificial tiene la capacidad de detectar la personalidad a través del lenguaje, crear un perfil, hasta saber si se enfada fácilmente.

Por su parte, el vocablo robótica fue acuńado por el escritor Isaac Asimov (1942), en su obra $R u$ naround (Círculo Vicioso, en español), para referirse a la disciplina científica que estudia a los robots. No existe una única definición, pero en general todas coinciden en que es una ciencia que estudia el diseño y construcción de máquinas capaces de desempeñar las tareas del ser humano mediante procesos mecanizados y programados, y como tal, requiere los conocimientos de varias disciplinas como álgebra, la informática, la electrónica, la mecánica, la física y la inteligencia artificial. Es de destacar la

27. Arend Hintze, "Understanding the four types of AI, from reactive robots to selfaware beings" The Conversation, (2016), acceso el 15 de octubre de 2020, http://theconversation.com/understanding-the-four-types-of-ai-from-reactiverobots-to-self-aware-beings-67616.

28. Stuart Russell y Peter Norvig, Inteligencia Artificial. Un Enfoque Moderno. $2^{\circ}$ Edición. (Madrid: Pearson Educación S.A, 2004) 3-9.

29. Noam Chomsky, Syntactic Structures (Paris: Mouton Publisher, 1957) 13-19. 
íntima asociación con la palabra robot, término inglés proveniente de la traducción del vocablo checo "robota", que significa trabajo servil o esclavo, vale decir, una especie de esclavo artificial que hace todo lo que el humano no quiere o no puede hacer. Tampoco hay una definición unánimemente aceptada. Entre las definiciones, se puede mencionar que "es una máquina, provista de cierta complejidad tanto en sus componentes como en su diseño o en su comportamiento, y que manipula información acerca de su entorno para así interactuar con él"30.

Barrio Andrés afirma que es prudente referirse al robot strictu sensu al que define como "aquel objeto mecánico que capta el exterior, procesa lo que percibe, y a su vez, actúa positivamente sobre el mundo"31. Y específicamente, la International Federation of Robotics (2018), en línea con la Norma Internacional ISO 8373:2012, Robots and robotic devices - Vocabulary, señala que un robot industrial es "un manipulador multiusos, reprogramable y controlado automáticamente, programable en tres o más ejes, que pueden estar fijos o móviles para uso en aplicaciones de automatización industrial”32.

Los robots coexisten en la sociedad del siglo XXI, sin embargo, ya en 1960 se utilizaron para tareas peligrosas o riesgosas como manejo de materiales tóxicos y radiactivos y cargar piezas en hornos y fundidoras. Algunas aplicaciones sencillas son las llamadas las tres D, en inglés Dark (oscuras), Dirty (sucias) y Dangerous (peligrosas), incluyendo tareas indeseables pero necesarias y también las tres $\mathrm{H}$, en inglés Hot (calientes), Heavy (pesadas) y Hazardous (riesgosas) ${ }^{33}$. Paulatinamente, se va ampliando la posibilidad de usos, desde los tradicionales modelos de fabricación utilizados en la industria clásica, hasta el tránsito por las ciudades, en reemplazo a los artefactos domésticos en las casas inteligentes y combatir en la guerra. Para realizar dichas tareas están equipados con efectores como piernas, ruedas, articulaciones sensores y pinzas con el objeto de percibir y transmitir fuerzas físicas al entorno. Hoy en día, utilizan diversos tipos de sensores, incluyendo cámaras y ultrasonidos para medir el entorno, y giroscopios y acelerómetros para medir el propio movimiento del robot ${ }^{34}$. La mayoría de los robots actuales se basan en una de las siguientes tres categorías, a saber:

a) manipuladores, o brazos robóticos, los que se encuentran físicamente anclados en su lugar de trabajo, por ejemplo, en una línea de ensamblaje o en la estación espacial internacional;

b) los robots móviles, lo que se desplazan por su entorno utilizando ruedas, piernas o mecanismos similares y

30 Juan García- Prieto Cuesta, “¿Qué es un robot?”, en Derecho de los Robots, dir. por Moisés Barrio Andrés (Madrid: Wolters Kluwer, 2018) 38.

31. Moisés Barrio Andrés (dir.) Derecho de los Robots (Madrid: Wolters Kluwer, 2018) 70.

32. International Federation of Robotics, The impact of Robots on Productivity, Employment and Jobs. (Frankfurt: International Federation of Robotics, 2018) 1.

33. Serope Kalpakjian y Steven Schmid, Manufactura, ingeniería y tecnología. $4^{\circ}$ Edición, (México: Pearson Educación, 2002) 1044.

34. Erica Palmerini, "Robótica y derecho: sugerencias, confluencias, evoluciones en el marco de una investigación europea”, Revista de Derecho Privado, Universidad Externado de Colombia, 32, (2017): 53-97. 
c) un tercer tipo que es un híbrido, que es un robot móvil equipado con manipuladores e incluye a los robots humanoides, cuyo diseño se asemeja al torso humano.

Siguiendo el razonamiento de Sánchez-Urán Azaña y Grau Ruiz, se puede clasificar a los robots conforme diferentes criterios según se tenga en cuenta su complejidad, sus componentes, su aplicación, y la influencia de la inteligencia artificial en la robótica, que le permite adquirir mayor capacidad en las tareas específicas y un cierto grado de impredecibilidad de su comportamiento. Lo antedicho ha ocasionado un debate sobre la denominada "falacia del Androide". En líneas generales, si bien se acepta que hay que entender las capacidades técnicas de los actuales robots, también se debe entender lo que nunca deberían hacer, vale decir, pensar en ellos como algo más que las máquinas que realmente $\operatorname{son}^{35}$.

En cuanto al grado de autonomía, se puede diferenciar entre los robots no autónomos que realizan tareas automatizadas; los autónomos y la inteligencia artificial aplicada a los robots que perciben el ambiente externo por si mismos, sin necesidad de ordenes pre programadas externas y con capacidad de discernir entre diferentes circunstancias que pueden acontecer a su alrededor. Estos sistemas deben obedecer tanto las órdenes de otros sistemas de inteligencia artificial como las humanas que interaccionan con él. No existe ningún robot hoy con estas características.

Un desafío a sortear por los desarrolladores de los robots es la paradoja de Moravec que consiste en que las máquinas son capaces de hacer cosas que son difíciles para los seres humanos, pero incapaces de aprender, habilidades psicomotrices o perceptivas que hasta un bebé posee ${ }^{36}$. Uno de los ejemplos más notables y difundidos llegó en el año de 1997, cuando la computadora conocida como Deep Blue, creada por IBM y que operaba como inteligencia artificial, derrotó al campeón mundial de ajedrez Gari Kasparov. El mayor problema de la máquina no consistió en resolver las partidas, que consiste en algoritmos simples, sino en tomar cada pieza con la fuerza justa para no romperla y poder ubicarla en el tablero, lo que cualquier niño podría realizar sin dificultad. A diferencia del software y de Internet, están diseñados para actuar sobre el mundo fuera de línea. Esta capacidad de actuar físicamente sobre el mundo real, se traduce en el potencial de dañar materialmente a las personas o a las cosas. Además, los robots más avanzados no repiten instrucciones, sino que se adaptan interactivamente a las circunstancias y presentan capacidad de aprendizaje incluso con la posibilidad de modificar su código.

Conforme los avances y ampliaciones de las diferentes prestaciones de la inteligencia artificial y la robótica, tanto la comunidad internacional como algunos Estados individualmente, comenzaron a intentar regular jurídicamente estas tecnologías disruptivas con el objeto de dotar de un marco legal y

35. María Yolanda Sánchez-Urán Azaña, y María Amparo Grau Ruiz, "El impacto de la Robótica, en especial la Robótica Inclusiva, en el trabajo: aspectos jurídico-laborales y fiscales.” Plataforma Digital Interuniversitaria sobre el Futuro del Trabajo. OIT, (6 de abril de 2018), acceso el 29 de octubre de 2020, desde https://iniciativaoitinteruniversitariafuturo deltrabajo.com/ver-articulos/item/el-impacto-de-la-robotica-en-especial-la-robotica-inclusiva-en-el-trabajoaspectos-juridico-laborales-y-fiscales.

36. Esther Paniagua, Future Trend Forum. Inteligencia Artificial, (Madrid: Fundación Innovación Bankinter, 2019$), 38$. 
ético tanto a los fabricantes, a los científicos como a los usuarios. En el seno del Parlamento Europeo, se dictaron las "Comunicaciones de la Comisión al Parlamento Europeo, al Consejo Europeo, al Consejo, al Comité Económico y Social Europeo y al Comité de las Regiones" sobre: "Inteligencia artificial para Europa", "Plan Coordinado sobre la Inteligencia Artificial", ambas en 2018 y "Generar confianza en la inteligencia artificial centrada en el ser humano", en 2019. En febrero de 2017, se adoptó una Resolución conteniendo recomendaciones a la Comisión para la elaboración de una normativa civil en materia de robótica, en 2019, la Resolución del Parlamento Europeo referida a la política industrial global europea en materia de inteligencia artificial y robótica y el Libro blanco sobre la inteligencia artificial del 2020. A nivel estadual, se destacan la Korean Law on the development and distribution of intelligent robots de 2005, Intelligent robots development and distribution promotion Act de 2008, ambas de Corea del Sur y Japan's New Robot Strategy y Robot Revolution Iniciative de 2015. Posteriormente, en 2012, el Ministerio de Comercio, Industria y Energía de Corea del Sur, mediante la Comisión de Ética de Robots, elaboró la "Carta de Ética Robótica" o "Robot Ethics Charter" y China, en julio de 2017, publicó el "Plan de desarrollo de inteligencia artificial de nueva generación".

\section{SISTEMAS ROBÓTICOS INTELIGENTES APLICADO AL COVID-19}

Los robots juegan un papel significativo en la lucha contra la pandemia COVID-19 y pueden realizar importantes contribuciones tanto a la industria como a la sociedad en su conjunto. Para el combate de esta enfermedad, es importante reducir el contacto estrecho entre las personas, principalmente en el sector médico donde se presenta la mayor proporción de contagios. En los países en donde todavía rige el aislamiento social obligatorio total o parcial, se utilizan para realizar tareas vitales en hospitales y residencias en pos de mantener a las personas seguras, alimentadas y con atención médica.

A comienzos de marzo, en plena pandemia, el presidente de China- Xi Jinping- hizo un llamamiento de colaboración al sector tecnológico para su combate. Si bien ya se estaban utilizado aplicaciones robóticas para el testeo y control de pacientes, el uso de nuevas tecnologías necesitaba dar un paso más adelante, principalmente en el trabajo con pacientes y en la sanitización de espacios comunes. Japón tampoco se quedó atrás y empleó su tecnología robótica para contener el coronavirus con un staff de robots en los hoteles sanitarios, donde se encontraban enfermos con síntomas leves para no colapsar los hospitales ${ }^{37}$. Dentro de las múltiples tareas que pueden desarrollar estas máquinas se puede mencionar:

\section{1. - Limpieza y desinfección}

Los robots se usan en hospitales para desinfectar habitaciones usando rayos ultravioleta que también matan el coronavirus. La desinfección ultravioleta puede destruir el 99,99\% de todos los microorganismos en una habitación de hospital en 10 minutos. Si bien la habitación debe estar vacía durante

37. Observatorio Parlamentario de Chile, "El aporte de los robots en China y Japón para la contención del coronavirus" Biblioteca del Congreso Nacional de Chile, (2020), acceso el 10 de diciembre de 2020, https://www.bcn.cl/observatorio/ asiapacifico/noticias/robotica-coronavirus-china-japon 
la desinfección, no hay efectos negativos de los rayos UV. El personal del hospital puede planificar la ruta del robot a través de una aplicación y, una vez activada, los robots de limpieza se mueven de forma autónoma de una habitación a otra. Al llegar, el autómata hace un anuncio pidiéndole a cualquiera que se encuentre dentro de ella, que se retire y cierre la puerta, en cuyo punto puede comenzar la limpieza. Actualmente, en Hong Kong, estos robots de limpieza se están utilizando para limpiar los vagones del tren, que transporta diariamente a millones de pasajeros. Con un nuevo diseńo complementa el trabajo humano al rociar con una solución de peróxido de hidrógeno todas las superficies, centrándose particularmente en pequeños espacios que las manos humanas no pueden alcanzar. Justamente colaborando y no reemplazando el trabajo humano.

En Irlanda, la empresa Akara, especializada en el diseño de ayudantes con inteligencia artificial para la industria de la salud, desarrolló Violet, la robot antiséptica, que combina la inteligencia artificial para desplazarse y la luz ultravioleta para destruir bacterias y complejas cepas virales. Para detectar y evitar a personas, Violet, está diseńada para utilizar sensores de movimiento, una unidad de procesamiento de visión y una plataforma de DepthAI de Luxonis para el seguimiento de inteligencia artificial, profundidad y características. Su tamaño compacto y su capacidad para operar de forma segura entre la gente hacen que sea apta para también ejecutar tareas fuera del hospital. Actualmente, el prototipo se está examinando para el sistema de transporte público de Dublín y también ha demostrado que tiene potencial para desinfectar otros lugares de mucho tránsito peatonal que son difíciles de limpiar, tales como baños, aeropuertos, hoteles, cruceros y salas de espera. Los científicos consideran que los robots como Violet cumplen un papel esencial para garantizar la seguridad de la población y podrían adaptarse todavía más para utilizar la visión computarizada para vigilar el distanciamiento social, garantizar el cumplimiento de las reglas del equipo de protección personal e incluso realizar el rastreo de contacto ${ }^{38}$.

También son de suma utilidad los vehículos aéreos no tripulados. La empresa de tecnología china DJI ha adaptado su serie de drones Agras -enfocados en el rociado agrícola- para esparcir desinfectante en áreas potencialmente afectadas. Los drones pueden mejorar notablemente los esfuerzos del país para erradicar el virus en áreas públicas, ya que son capaces de cubrir mucho más terreno que los métodos tradicionales y reducen el riesgo para los trabajadores, al limitar la exposición al virus ${ }^{39}$.

\section{2.- En colaboración con el personal médico y de laboratorio}

Se refiere al tratamiento de pacientes con coronavirus, lo que permite a los médicos y enfermeras realizar pruebas e interactuar sin contacto físico. El primer paciente estadounidense diagnosticado con el virus fue tratado por un robot controlado a distancia, equipado con un estetoscopio y una pantalla que permitía a los médicos y enfermeras comunicarse con el enfermo y tomar medidas simples.

38. "Robots autónomos que combaten virus luchan contra el COVID-19", Intel(s.f.), acceso el 19 de diciembre de 2020, https://www.intel.la/content/www/xl/es/corporate-responsibility/akara-fight-against-covid19-article.html

39. ContentLab, "Salud: 5 Robots que batallan contra el Coronavirus" Revista Gestion. pe, (2020), acceso el 14 de diciembre de 2020, https://gestion.pe/especial/businessstyle/innovacion/salud-5-robots-que-batallan-contra-coronavirus-noticia-1994925 
Los robots colaborativos de KUKA y Universal Robots, líderes mundiales en el suministro de robótica, están siendo ampliamente utilizados para automatizar el trabajo de laboratorio. Actualmente el Instituto de Automatización Shenyang de la Academia China de Ciencias, se encuentra ensayando un robot que automatiza el proceso de toma de hisopos bucales para detectar el virus. Y la empresa china de robótica CloudMinds ayudó a establecer un hospital de campaña dirigido por robots durante el brote de coronavirus en Wuhan.

En Italia, en la región de Lombardía se popularizó el robot “Tommy” que asiste a los doctores del Hospital Circolo en la ciudad de Varese, cumpliendo las funciones de un enfermero. Tommy se queda al lado de la cama del paciente para que los médicos puedan atender a otros, monitorea los equipos médicos de la habitación, transmite la información al personal y permite a los pacientes grabar y enviar mensajes a los médicos.

En varios hospitales de Tailandia, con anterioridad a la pandemia, se utilizaba una flota de androides llamados Ninja cuya misión consistía en asistir a personas que sufrían de accidentes cerebrovasculares como infartos cerebrales, derrames cerebrales o apoplejías. Actualmente su función radica en identificar a las personas afectadas por coronavirus, cuidar de ellas y proteger al personal sanitario del contagio.

Los robots, dotados de la tecnología 4G, pueden detectar la temperatura de un paciente, supervisar la evolución de los síntomas y permitir al personal sanitario y los internos conectarse por videoconferencia. Pero también existen robots cirujanos, el primero de ellos fue Da Vinci, creado en el año 2000, se utiliza en cirugías complejas de manera menos invasiva. Es de destacar que entre los robots médicos existen algunos minúsculos como ViRob, de 14 milímetros que se mueve por las venas, arterias o cualquier cavidad del cuerpo humano y sirve para explorar zonas del organismo donde un endoscopio o cámara normal no llegarían, además de ser capaz de llevar medicamentos o realizar pequeñas incisiones sin necesidad de realizar una cirugía ${ }^{40}$.

El médico especialista en cuidados intensivos Óscar García-Esquirol y el ingeniero industrial Cristian Pascual desarrollaron una app gratuita, denominada Mediktor, que se utiliza para evaluar los síntomas del coronavirus mediante inteligencia artificial. En base a la información proporcionada, valora el riesgo de estar infectado y el grado de urgencia que necesitaría el usuario.

En igual sentido, el hospital Clínic de Barcelona, conjuntamente con el Barcelona Supercomputing Center, han desarrollado una tecnología capaz de obtener un diagnóstico fiable de la evolución de la enfermedad en cada paciente y, por tanto, un mejor tratamiento. Primero, se recurre a la llamada minería de textos, consistente en alimentar a la máquina con los informes médicos de más de 3.000 pacientes y, mediante algoritmos de predicción- machine learning- se entrena a la máquina con un $80 \%$ de los casos de covid-19. La precisión de esos diagnósticos se logra comparándolos con el $20 \%$ restante de

40. Belén Juárez, “Ninja', el robot médico que lucha contra el coronavirus”. Diario El País, 26 de abr. de 2020, sección Tecnología, acceso el 11 de diciembre de 2020, https://elpais.com/tecnologia/2020-04-26/ninja-el-robot-medico-que-lucha-contra-el-coronavirus.html. 
diagnósticos, comprobando así si la inteligencia artificial ha acertado en sus predicciones de curación, gravedad o muerte por el virus. De esta forma, los profesionales de la salud pueden saber si el paciente va a requerir asistencia respiratoria, si va a necesitar ingresar en Unidad de Cuidados Intensivos o si va a fallecer ${ }^{41}$.

\section{3.- Grupos de riesgo}

En la pandemia COVID-19, los adultos mayores son considerados grupos de riesgo, por lo que la mayoría de los países aconsejan o, en algunos casos, exigen que las personas mayores permanezcan en sus casas y se abstengan de contactar a los miembros de la familia que no conviven con ellos. Los robots de telepresencia asisten a los adultos mayores para que puedan vivir en forma independiente durante más tiempo. La imagen del usuario remoto se muestra en la pantalla del robot y se lo puede dirigir por la habitación para ver cualquier cosa que se encuentre cerca. La mayoría de estos robots son controlables desde cualquier lugar con un teléfono inteligente o computadora y conexión a Internet. Los miembros de la familia, amigos, médicos y cuidadores pueden iniciar sesión conducirlo, interactuar con otros y explorar el entorno con audio y video.

La compañía Hanson Robotics, creadora de la robot humanoide Sophia, anunció que producirá en forma masiva miles de robots para finales del año 2021 con el fin de cuidar a ancianos y afectados por el coronavirus o simplemente para acompañarlos. Las principales funciones de Sophia consisten en mantener una conversación y mostrar una variedad de expresiones faciales. Es capaz de entender y transmitir emociones gracias a su tecnología de procesamiento de lenguaje natural y redes neuronales artificiales. Sophia entiende el aspecto emocional que acarrean las palabras y eso puede utilizarlo para expresar gestos faciales que transmiten esas emociones. Actualmente está desarrollando más prototipos como Grace y Hanson con mayores funcionalidades como el cuidado de la salud, la toma de temperatura o la realización de ejercicios aeróbicos ${ }^{42}$.

\section{4.-Delivery}

Estos autómatas se pueden utilizar en una amplia variedad de sectores para entregar piezas, suministros y alimentos. Los robots de entrega ya se usan en los hospitales para los suministros médicos y artículos pesados como ropa de cama. Por lo general, entregan artículos en el sector de enfermería, pero hoy en día, se están utilizando para hacer entregas directamente a pacientes aislados tanto en hospitales como en otros lugares. Por ejemplo, los robots llevaron alimentos a personas que habían estado en un

41. Héctor Pérez, "Inteligencia artificial: la gran aliada contra la covid-19" Revista Compromiso Empresarial (2020), acceso el 1 de febrero de 2021, https://www.compromisoempresarial.com/coronavirus/2020/11/inteligencia-artificial-aliada-contra-covid19/

42. "La robot que prometió "destruir a la humanidad" llega al mercado masivo: cuánto costará y quién lo vende" Infotechnology, 28 de ene. de 2021, acceso el 5 de febrero de 2021, https://www.infotechnology.com/innovacion/la-robot-queprometio-destruir-a-la-humanidad-llega-al-mercado-masivo-cuanto-costara-y-quien-lo-vende/ 
vuelo con pasajeros infectados con el virus y que posteriormente tuvieron que cumplir con la cuarentena en un hotel en Hangzhou, China. El robot anuncia su llegada a la puerta y el ocupante saca su bandeja de comida del estante incorporado en el mismo.

Pudu Robotics Co. Ltd., empresa nacional china de alta tecnología dedicada al diseño, fabricación y venta de robots de reparto, ha suministrado cientos de Pudubot a varios hospitales de Seúl (Corea del Sur), Pekín y Wuhan (China). Estos robots son completamente automáticos y pueden realizar el proceso de reparto por sí mismos. Con una bandeja de gran capacidad, son aptos para repartir una importante cantidad de medicinas, comidas y otros suministros a los pacientes de los hospitales y así reducir la carga del personal médico ${ }^{43}$. Y ya opera el robot Roxo, de FedEx - fabricado por Keenon Robotics -, que permite transportar medicinas y alimentos a personas en zonas de aislamiento.

En Seúl, "Aglio Kim”, un robot con forma de carro que utiliza inteligencia artificial, entrega comida a los clientes en un restaurante con el fin de minimizar el contacto entre las personas y ayudar a asegurar el distanciamiento físico. Los clientes hacen el pedido a través de una pantalla táctil en la mesa, el robot de 1,25 metros de altura, desarrollado por la empresa de telecomunicaciones de Corea del Sur KT Corp, se las lleva y utiliza sus habilidades visuales de localización y mapeo simultáneos para evitar obstáculos y transitar entre los clientes. El robot puede entregar comida hasta en cuatro mesas a la vez a que está equipado con bandejas de comida que pueden transportar hasta 30 kilogramos, una pantalla LCD y un altavoz que permiten la comunicación tanto en coreano como en inglés ${ }^{44}$.

Por su parte, Amazon presentó a Scout, un robot de seis ruedas eléctrico y autónomo que puede llevar paquetes a un ritmo de caminata. Y desde 2016, la compañía Just Eat, lleva trabajando en Yape, un robot de entrega a domicilio ${ }^{45}$.

En igual sentido, en Milton Keynes, al norte de Inglaterra, y en la ciudad de Medellín, Colombia, una gran cantidad de robots delivery comenzaron a transitar por las calles en entrega de mercaderías.

\section{5.- Elaboración de comidas}

En China, se han utilizado para preparar y servir alimentos a los trabajadores médicos, de modo que los comedores de los hospitales no necesiten personal las 24 horas del día. Según los informes, un

43. Ben Zheng, "Ante la COVID-19, Pudu Robotics provee de un servicio de reparto sin contacto en cientos de hospitales de todo el mundo". Businesswire, 5 de jun. de 2020, acceso el 1 de diciembre de 2020, https://www.businesswire.com/ news/home/20200605005279/es/

44. Minwoo Park "Robot con inteligencia artificial atiende a clientes en restaurante de Seúl" Reuters, 15 de sep. de 2020, acceso el 20 de diciembre de 2020, https://www.reuters.com/article/salud-coronavirus-coreadelsur-robot-idLTAKBN26620O.

45. "Delivery con robots: cómo este concepto de ciencia ficción se convirtió en realidad con la pandemia", iProUP, 26 de sept. de 2020, acceso el 20 de diciembre de 2020, https://www.iproup.com/innovacion/17093-robots-puerta-a-puertamodo-de-delivery-que-crece-en-pandemia. 
robot de preparación de alimentos elaboró en un hospital en Wuhan -China- 36 porciones de cazuela de arroz cada 15 minutos $^{46}$.

\section{6.- Vigilancia}

La medición manual de la temperatura corporal expone al personal de seguridad pública a riesgos potenciales para la salud. Los robots de vigilancia o patrullaje están equipados con hasta cinco cámaras de alta resolución y termómetros infrarrojos y son capaces de escanear simultáneamente la temperatura de diez personas en un radio de cinco metros. En caso de detectar una temperatura alta o la ausencia de una máscara, enviarían una alerta a las autoridades pertinentes. Una de las primeras empresas en implantar este sistema de patrullaje inteligente fue Shenhao Technology, con su robot "Health Guardian $1 "$ "

En Singapur se implementó un perro robot llamado "Spot" el cual está diseñado para transitar por las calles y espacios públicos a fin de comprobar que las personas cumplan con el distanciamiento social. Spot tiene sensores y cámaras de 360 grados, puede correr a una velocidad de 1,6 metros por segundo y es capaz de soportar temperaturas desde los -20 grados centígrados hasta los 45 grados centígrados. También emite diferentes mensajes a la comunidad relacionados con la importancia de mantener el aislamiento social ${ }^{48}$.

Y la Ciudad Autónoma de Buenos Aires, Argentina, el 8 de diciembre de 2020, implementó un nuevo protocolo para el ingreso de turistas internacionales y nacionales. Específicamente los turistas nacionales que ingresen por otros medios que no sean avión o micro, en las primeras 24 horas de su arribo deben acudir a los Centros de testeos dispuestos a tales efectos por la Ciudad. Para ellos se desarrolló un sistema de envío de SMS en el momento que ingresen a la Ciudad que detecta, mediante las antenas telefónicas, aquellos números distintos al 011 y que provienen de más de $150 \mathrm{kms}$. El objetivo es poder informarles respecto de la normativa y contactarlos con Boti, el WhatsApp de la Ciudad, para que conozcan cuál es el punto más cercano donde se realiza la toma de muestra de saliva para el test $\mathrm{PCR}^{49}$.

46. International Federation of Robotics, "Robots on the front line of keeping people safe from the coronavirus", IFR Secretariat Blog, 1 de abr. de 2020, acceso el 27 de noviembre de 2020, https://ifr.org/post/robots-on-the-front-line-ofkeeping-people-safe-from-the-coronavirus

47. Vanesa García, "Robots de patrullaje inteligentes luchan contra Covid-19”. Revista byte, (2020), acceso el 20 de diciembre de 2020, https://revistabyte.es/covid-19/robots-de-patrullaje/

48. La pandemia, ¿excusa perfecta para que nos reemplacen los robots?, El Tiempo, 14 de jun. de 2020, acceso el 3 de octubre de 2020, https://www.eltiempo.com/tecnosfera/novedades-tecnologia/paises-comienzan-a-usar-robots-para-atender-la-pandemia-del-nuevo-coronavirus-505066

49. Buenos Aires Ciudad, "El protocolo de ingreso, al detalle" Buenos Aires Ciudad BA, 8 de dic. de 2020, acceso el 8 de diciembre de 2020, https://www.buenosaires.gob.ar/noticias/como-es-el-protocolo-para-el-ingreso-de-turistas-la-ciudad 


\section{CONCLUSIONES}

Resulta innegable que los efectos de la pandemia interpelaron a la humanidad y evidenciaron las grandes desigualdades y discriminaciones generales tanto en el acceso a los bienes básicos, como sistemas de salud insuficientes, trabajos precarizados, grandes hambrunas e inseguridad alimentaria como en la creciente brecha digital. El mundo pospandemia plantea grandes desafíos y oportunidades en cuanto a la utilización de la inteligencia artificial y la acelerada digitalización de las sociedades. El reto es acortar esa brecha digital y no replicar las tradicionales diferencias entre las naciones y entre las regiones del mismo país.

Sin embargo, los avances tecnológicos permitieron que la humanidad se pudiera conectar a pesar de la distancia física y así se transformó la modalidad de trabajo, de estudio y, como fue ejemplificado en este trabajo, se utilizaron los sistemas robóticos inteligentes en hospitales, para asistir a los grupos vulnerables, en vigilancia, en la industria alimenticia y en seguimiento y control de la enfermedad. Ahora que en casi todas las partes del mundo se está asistiendo a una segunda ola de contagios y de mutación del virus, la pandemia sigue conviviendo con la humanidad y una nueva realidad se abrió camino en todos los puntos del planeta: la necesaria utilización de las nuevas tecnologías y la coexistencia entre humanos y máquinas.

El presente artículo se planteó, como interrogante, si la inteligencia artificial aplicada a la robótica puede colaborar con los seres humanos en la reducción de la propagación del virus SARS-CoV-En respuesta a tal cuestionamiento, y una vez aclarados los conceptos, se ejemplificó la contribución de dichas tecnologías disruptivas en la actual crisis sanitaria para el bienestar de la salud mundial en el contexto de la pandemia y pospandemia. La cooperación en el mismo ámbito de trabajo entre humanos y robots resultó indispensable para mantener la integridad de los trabajadores de la salud y de los grupos vulnerables más afectados por esta enfermedad. Estas pequeñas máquinas, con aspecto amigable resultaron aliadas para el bien, realizando tareas riesgosas para los individuos. Sin embargo, la humanidad se enfrenta a un gran desafío que consiste en determinar la manera regular estas nuevas tecnologías sin frenar los avances tecnológicos. Es necesario establecer un marco jurídico y ético propio, específico y que en todo momento se mantenga la supervisión y el control humano y el resguardo de los datos personales.

Específicamente los datos sensibles para evitar replicar en los softwares cualquier sesgo discriminatorio, en especial en materia sanitaria. Al acopiar los datos biométricos, los gobiernos y las empresas pueden saber sobre cada ser humano mucho más de lo que hasta ahora podían conocer. Por tanto, lo ideal sería que un sistema de vigilancia funcionara bajo el control de una autoridad sanitaria y que recolecte el mínimo necesario de datos para cumplir con la tarea específica de prevenir epidemias.

Finalmente, recordamos las palabras de la escritora, periodista y activista india Arundhati Roy "Históricamente, las pandemias han obligado a los seres humanos a romper con el pasado e imaginar su mundo de nuevo. Esta no es diferente. Es un portal, una puerta entre un mundo y el siguiente" 50 .

50. Arundhati Roy, "La pandemia es un portal", La Jornada, 13 de abr. de 2020, acceso el 14 de abril de 2020, 


\section{REFERENCIAS}

- Asimov, Isaac. Círculo Vicioso. 1942. Acceso el 2 de septiembre de 2020 desde http://inteligenciaeducativa.net/descargas/runaround.pdf

- $\quad$ Barrio Andrés, Moisés. (dir.) Derecho de los Robots. Madrid: Wolters Kluwer, 2018.

- Brynjolfsson, Erik. y McAfee, Andrew. The Second machine Age. New York/London: W.W. Norton \& Company, 2014.

- $\quad$ Buenos Aires Ciudad. "El protocolo de ingreso, al detalle" Buenos Aires Ciudad BA. 8 de dic. de 2020. Acceso el 8 de diciembre de 2020 desde https://www.buenosaires.gob.ar/noticias/como-es-el-protocolo-para-el-ingreso-de-turistas-la-ciudad

- Cáceres Nieto, Enrique. "Constructivismo jurídico e inteligencia artificial en el proyecto CONACYT-IIJ-CCADET-TSJT”. Revista El Siete. Revista Jurídica Estudiantil Departamento de Derecho Universidad de Sonora 2, 7, México: Universidad de Sonora, (2006): 2-16.

- Comité de Derechos Económicos, Sociales y Culturales. Observación General N 14: El derecho al disfrute del más alto nivel posible de salud (artículo 12 del Pacto Internacional de Derechos Económicos, Sociales y Culturales) E/C.12/2000/4, 2000.

- Comisión Europea, “Comunicación de la Comisión al Parlamento Europeo, al Comité Económico y Social Europeo y al Comité de las Regiones: Inteligencia Artificial para Europa”, (COM, 237 final, 25 de abril de 2018), 1.

- ContentLab. "Salud: 5 Robots que batallan contra el Coronavirus" Revista Gestion. pe. (2020) Acceso el 14 de diciembre desde https://gestion.pe/especial/businessstyle/innovacion/salud-5-robots-que-batallan-contracoronavirus-noticia-1994925

- Chomsky, Noam. Syntactic Structures. Paris: Mouton Publisher, 1957. https://doi.org/10.1515/9783112316009

- De Quiroga, Santiago. “2021: ¿Comienza la era de los coronavirus?” Gaceta Médica (2020) Acceso el 5 de febrero de 2021desde https:/gacetamedica.com/opinion/la-contra/2021-comienza-la-era-de-los-coronavirus/

- "Delivery con robots: cómo este concepto de ciencia ficción se convirtió en realidad con la pandemia”, iProUP, 26 de sept. de 2020. Acceso el 20 de diciembre de 2020, desde https://www.iproup.com/innovacion/17093-robots-puerta-a-puerta-modo-de-deliveryque-crece-en-pandemia

https://www.jornada.com.mx/ultimas/mundo/2020/04/13/la-pandemia-es-un-portal-9285.html 
- $\quad$ Espasa Calpe. Diccionario Enciclopédico Espasa. Inteligencia. 3 Madrid: Espasa Calpe, 1993.

- García- Prieto Cuesta, Juan. “¿Qué es un robot?”. En Derecho de los Robots, dir. por Moisés Barrio Andrés. Madrid: Wolters Kluwer, 2018.

- García, Vanesa. "Robots de patrullaje inteligentes luchan contra Covid-19”. Revista byte. (2020). Acceso el 20 de diciembre de 2020 desde https://revistabyte.es/covid-19/robots-de-patrullaje/

- Gómez, Ángela, "Alemania anuncia "un nuevo confinamiento duro" ante el aumento de los contagios por COVID-19”, France 24, 13 de dic. de 2020. Acceso el 18 de diciembre de 2020 desde

https://www.france24.com/es/europa/20201213-covid19hoy-alemania-cierra-de-nuevo-lanavidad-ser\%C3\%A1-en-aislamiento

- Hintze, Arend. "Understanding the four types of AI, from reactive robots to selfaware beings". The Conversation (2016). Acceso el 15 de octubre de 2020, desde http://theconversation.com/understanding-the-four-types-of-ai-from-reactive-robots-to-self-awarebeings-67616

- International Federation of Robotics. Executive Summary World Robotics 2020 Industrial Robots. Frankfurt: International Federation of Robotics, 2020.

- International Federation of Robotics. Executive Summary World Robotics 2020 Service Robots. Frankfurt: International Federation of Robotics, 2020.

- International Federation of Robotics. The impact of Robots on Productivity, Employment and Jobs. Frankfurt: International Federation of Robotics, 2018

- International Federation of Robotics. World Robotics 2019 - Industrial Robots and Service Robots. Frankfurt: International Federation of Robotics, 2019.

- International Federation of Robotics (1 april, 2020) "Robots on the front line of keeping people safe from the coronavirus", IFR Secretariat Blog, 1 de abr. De 2020. Acceso el 27 de noviembre de 2020 desde https://ifr.org/post/robots-on-the-front-line-of-keeping-people-safe-from-the-coronavirus

- Juárez, Belén.“'Ninja', el robot médico que lucha contra el coronavirus”. Diario El País, 26 de abril de 2020, sección Tecnología. Acceso el 11 de diciembre de 2020 desde https://elpais.com/tecnologia/2020-04-26/ninja-el-robot-medico-que-lucha-contra-elcoronavirus.html 
- Kalpakjian, Serope y Schmid, Steven. Manufactura, ingeniería y tecnología. $4^{\circ}$ Edición. México: Pearson Educación, 2020.

- Kaplan, Andreas y Haenlein, Michael. "Siri, Siri in my Hand, who's the Fairest in the Land? On the Interpretations, Illustrations and Implications of Artificial Intelligence". Business Horizons 62, 1 (2018): 15-25. https://doi.org/10.1016/j.bushor.2018.08.004

- Keidanren. Society 5.0. Co-creating the future (2018) Acceso el 18 de diciembre de 2020, desde https:/www.keidanren.or.jp/en/policy/2018/095.html

- La pandemia, ¿excusa perfecta para que nos reemplacen los robots? () El Tiempo. 14 de jun. de 2020. Acceso el 3 de octubre de 2020 desde https://www.eltiempo.com/tecnosfera/novedades-tecnologia/paises-comienzan-a-usarrobots-para-atender-la-pandemia-del-nuevo-coronavirus-505066

- "La robot que prometió "destruir a la humanidad" llega al mercado masivo: cuánto costará y quién lo vende" Infotechnology, 28 de ene. de 2021. Acceso el 5 de febrero de 2021, desde https:/www.infotechnology.com/innovacion/la-robot-que-prometio-destruir-a-lahumanidad-llega-al-mercado-masivo-cuanto-costara-y-quien-lo-vende/

- López de Mántaras, Ramón citado en: Esther Paniagua Future Trend Forum. Inteligencia Artificial. Madrid: Fundación Innovación Bankinter, 2019.

- McCarthy, John. "What Is Artificial Intelligence" Universidad de Stanford. Sección Basic Questions. (2007). Acceso el 8 de febrero de 2020 desde http://www-formal.stanford.edu/jmc/whatisai/node1.html

- Observatorio Parlamentario de Chile. "El aporte de los robots en China y Japón para la contención del coronavirus" Biblioteca del Congreso Nacional de Chile. (2020) Acceso el 10 de diciembre de 2020 desde https://www.bcn.cl/observatorio/asiapacifico/noticias/robotica-coronavirus-china-japon

- Oficina del Alto Comisionado de las Naciones Unidas para los Derechos Humanos y Organización Mundial de la Salud. El derecho a la salud. Folleto Informativo No 31. Nueva York: Oficina del Alto Comisionado de las Naciones Unidas para los Derechos Humanos, 2008.

- Organización Mundial de la Salud. Constitución de la Organización Mundial de la Salud. Nueva York: OMS, 1946. Acceso el 1 de febrero de 2021, desde https://apps.who.int/gb/bd/PDF/bd48/basic-documents-48th-edition-sp.pdf?ua=1\#page=7 
- Organización Mundial de la Salud Carta de Ottawa para la Promoción de la Salud. Ottawa: OMS, 1986.

- Organización Mundial de la Salud. "Brote de enfermedad por coronavirus (COVID-19)". (2020). Acceso del 15 de noviembre de 2020 desde https://www.who.int/es/emergencies/diseases/novel-coronavirus-2019?gclid=CjwKCAjw_-

D3BRBIEiwAjVMy7LoQ-sw-m1weY0UFQ2vweql1FItqwPSLkmiE4_cdEPuF-kgiiAevVBo C7RcQAvD_BwE

- Organización Mundial de la Salud. "La OMS presenta reformas de gran envergadura para alcanzar las metas de los "tres mil millones". 6 de marzo de 2019. Acceso el 10 de noviembre de 2020 desde

https://www.who.int/es/news-room/detail/06-03-2019-who-unveils-sweeping-reformsin-drive-towards-triple-billion-targets

- Ortega, Andrés “Sociedad 5.0: el concepto japonés para una sociedad superinteligente”. Estudios Internacionales y Estratégicos, ARI 10-2019, España, Real Instituto Elcano (2019). Acceso el 3 de agosto de 2020, desde http://www.realinstitutoelcano.org/wps/portal/rielcano_es/contenido?WCM_ GLOBAL_CONTEXT=/elcano/elcano_es/zonas_es/economia+internacional/ari10-2019ortega-sociedad-5-0-concepto-japones-sociedad-superinteligente\#: - :text=En

- Palmerini, Erica. (2017) "Robótica y derecho: sugerencias, confluencias, evoluciones en el marco de una investigación europea”. Revista de Derecho Privado. Universidad Externado de Colombia, 32, (2017): 53-97. https://doi.org/10.18601/01234366.n32.03

- Paniagua, Esther. Future Trend Forum. Inteligencia Artificial. Madrid: Fundación Innovación Bankinter, 2019.

- Park, Minwoo. "Robot con inteligencia artificial atiende a clientes en restaurante de Seúl" Reuters, 15 de sep. de 2020. Acceso el 20 de diciembre de 2020, desde https://www.reuters.com/article/salud-coronavirus-coreadelsur-robot-idLTAKBN26620O

- Pérez, Héctor. "Inteligencia artificial: la gran aliada contra la covid-19" Revista Compromiso Empresarial (2020). Acceso el 1 de febrero de 2021 desde https://www.compromisoempresarial.com/coronavirus/2020/11/inteligencia-artificialaliada-contra-covid19/

- Pérez Luño, Antonio "Sistemas expertos jurídicos: premisas para un balance”. En Calculemos... Matemáticas y libertad, coords. Lorenzo Peña, Javier de Lorenzo Martínez y Javier Echeverría Ezponda, 273-300. España: Trotta, 1996. 
- "Reino Unido, virtualmente aislado por el brote de una nueva cepa más contagiosa" Telam, 21 de dic. de 2020. Acceso el 22 de diciembre de 2020, desde https://www.telam.com.ar/notas/202012/539175-reunion-crisis-reino-unido-fronterafrancia.html

- "Robots autónomos que combaten virus luchan contra el COVID-19". Intel (s.f.) Acceso el 19 de diciembre de 2020 desde https://www.intel.la/content/www/xl/es/corporate-responsibility/akara-fight-againstcovid 19-article.html

- $\quad$ Roy, Arundhati. "La pandemia es un portal”, La Jornada, 13 de abr. de 2020. Acceso el 14 de abril de 2020, desde https://www.jornada.com.mx/ultimas/mundo/2020/04/13/la-pandemia-es-un-portal-9285.html

- $\quad$ Russell, Stuart y Norvig, Peter. Inteligencia Artificial. Un Enfoque Moderno. $2^{\circ}$ Edición. Madrid: Pearson Educación S.A, 2004.

- Sánchez-Urán Azaña, María Yolanda y Grau Ruiz, María Angélica. "El impacto de la Robótica, en especial la Robótica Inclusiva, en el trabajo: aspectos jurídico-laborales y fiscales." Plataforma Digital Interuniversitaria sobre el Futuro del Trabajo. OIT. 6 de abril de 2018. Acceso el 29 de octubre de 2020 desde https://iniciativaoitinteruniversitariafuturodeltrabajo.com/ver-articulos/item/elimpacto-de-la-robotica-en-especial-la-robotica-inclusiva-en-el-trabajo-aspectos-juridicolaborales-y-fiscales

- Searle, John (1980) "Minds, brains, and programs". Behavioral and Brain Science 3, 3 (1980): 417-424. https://doi.org/10.1017/S0140525X00005756

- Shwab, Klauss. La Cuarta revolución Industrial. España: Debate, 2016.

- Torres, Mariano. Derechos y desafíos de la Inteligencia Artificial, Buenos Aires: CyTA, 2019

- Zheng, Ben. "Ante la COVID-19, Pudu Robotics provee de un servicio de reparto sin contacto en cientos de hospitales de todo el mundo". Businesswire. 5 de jun. de 2020 Acceso el 1 de diciembre de 2020 desde https://www.businesswire.com/news/home/20200605005279/es/

RECIBIDO: 17/02/2021

APROBADO: 15/04/2021 